\title{
Estimativas de parâmetros genéticos da variedade BR 5028-São Francisco no Nordeste brasileiro(1)
}

\author{
Hélio Wilson Lemos de Carvalho(2), Manoel Xavier dos Santos ${ }^{(3)}$, Maria de Lourdes da Silva Leal(2) \\ e Evanildes Menezes de Souza(2)
}

\begin{abstract}
Resumo - O objetivo deste trabalho foi obter estimativas dos parâmetros genéticos da variedade de milho BR 5028-São Francisco, submetida a 13 ciclos de seleção entre e dentro de progênies de meios-irmãos em diferentes municípios dos estados de Sergipe e Bahia. As estimativas da variância genética aditiva decresceram após os três primeiros ciclos de seleção, registrando-se uma redução drástica do ciclo I para o II, provocada pelo estresse de umidade. O ganho médio esperado com a seleção entre e dentro de progênies de meios-irmãos, por ciclo de seleção, nos três ciclos iniciais, foi de 10,6\%. A variabilidade genética dessa variedade permaneceu a mesma nos ciclos VI e VII, quando a seleção foi praticada em um só local. Foi observado aumento dessa variabilidade a partir do ciclo VIII, permanecendo constante entre os ciclos IX e XV, quando a seleção foi praticada em mais de um local. Os ganhos médios esperado e obtido (ciclo/ano) entre os ciclos VI e XV foram de 20,0\% e 4,03\%, respectivamente. As magnitudes das estimativas dos parâmetros genéticos, no decorrer de sucessivos ciclos de seleção, justificam a continuidade do programa de melhoramento para aumentar a produção.
\end{abstract}

Termos para indexação: Zea mays, irmãos, progênie, seleção, variação genética.

\section{Genetic parameters estimates in the maize variety BR 5028-São Francisco in the Brazilian Northeast region}

\begin{abstract}
The objective of this work was to obtain genetic parameters estimates in the maize variety BR 5028-São Francisco, submitted to 13 selection cycles among and within half sib families, in Sergipe and Bahia states. The additive genetic variance estimates reduced after the first three selection cycles with a drastic reduction from cycle I to cycle II due to moisture stress. The expected mean gain when the selection was done in one environment, by selection cycle, during the first three cycles was $10.6 \%$. In the selection cycles VI and VII, the genetic variability was stable. In cycle VIII an increase of variability was observed and then, stabilized between cycles IX and XV, when the selection was done in more than one environment. The expected and obtained mean gain (cycle/year) between cycles VI and XV were $20.0 \%$ and $4.03 \%$, respectively. The obtained values of the genetic parameters estimates justify the continuity of maize breeding program to increase the production.
\end{abstract}

Index terms: Zea mays, siblings, progeny, selection, genetic variation.

\section{Introdução}

Coexistem no Nordeste brasileiro diferentes sistemas de produção de milho, predominando os dos

\footnotetext{
(1) Aceito para publicação em 20 de junho de 2003.

${ }^{(2)}$ Embrapa-Centro de Pesquisa Agropecuária dos Tabuleiros Costeiros, Av. Beira Mar, 3250, Caixa Postal 44, CEP 49001-970 Aracaju, SE. E-mail: helio@cpatc.embrapa.br, lurdinha@cpatc.embrapa.br, eva@cpatc.embrapa.br

${ }^{(3)}$ Embrapa-Centro Nacional de Pesquisa de Milho e Sorgo, Caixa Postal 152, CEP 35701-970 Sete Lagoas, MG. E-mail: xavier@cnpms.embrapa.br
}

pequenos e médios produtores rurais, que utilizam o milho, o feijão, o arroz e a mandioca como fonte de sustento familiar em escala de produção tradicional, com baixas produtividades, associadas a fatores econômicos e culturais dos produtores e à não-utilização de tecnologias adequadas para a produção. A maior parte dos produtores de milho não pode adotar tecnologias que demandem aumentos nos custos de produção e a utilização de variedades melhoradas pode aumentar substancialmente o rendimento da cultura. As sementes de variedades melhoradas são insumos baratos e acessíveis, se constituem em uma 
tecnologia de fácil adoção e podem ser reutilizadas em plantios subseqüentes.

As estimativas das variâncias genéticas são realizadas, em grande parte, utilizando-se progênies de meios-irmãos, de onde estimam-se a variância genética aditiva, a herdabilidade e o ganho por seleção. $\mathrm{O}$ esquema de seleção entre e dentro de progênies de meios-irmãos vem sendo praticado com sucesso, conforme assinalam Paterniani (1968), Sawazaki (1979) e Hallauer \& Miranda Filho (1988). Esses últimos, em um levantamento envolvendo 99 trabalhos, comprovaram a eficiência desse método de seleção, e concluíram que ele é capaz de manter suficiente variabilidade genética para propiciar ganhos no decorrer dos ciclos sucessivos de seleção.

Resultados satisfatórios, quanto aos ganhos esperados em produtividade de espigas, vêm sendo obtidos no Nordeste brasileiro, com diversas populações de milho, conforme segue: diversos ciclos da variedade BR 5033-Asa Branca (Carvalho et al., 2000d); com a população CMS 52 (Carvalho et al., 2000b); com a população CMS 453 (Carvalho et al., 2000a, 2001); e com diversos ciclos da variedade BR 5011-Sertanejo (Carvalho et al., 2000c), cuja seleção entre e dentro de progênies de meios-irmãos vem sendo realizada sem sementes remanescentes (um ciclo por ano), o que, segundo Ramalho (1977), proporciona ganhos anuais maiores do que com o uso de sementes remanescentes (um ciclo a cada dois anos). Essa vantagem é tanto maior quanto maior for a intensidade de seleção entre progênies e maior for a magnitude de variância aditiva (Ramalho, 1977). Os primeiros resultados nessa região foram obtidos por Santos \& Naspolini Filho (1986), submetendo a variedade Dentado Composto Nordeste a quatro ciclos de seleção entre e dentro de progênies de meios-irmãos, realizando duas gerações por ano. Esses autores constataram a eficiência do método de seleção entre e dentro de progênies de meios-irmãos para melhorar a produtividade de grãos dessa variedade, enfatizando que, nos ciclos subseqüentes, devese dar maior ênfase à seleção entre progênies do que dentro de progênies. Essa mesma tendência foi observada por Paterniani (1968), Sawazaki (1979) e Carvalho et al. (2000a, 2000b, 2000c).

O objetivo deste trabalho foi obter estimativas dos parâmetros genéticos da variedade de milho
BR 5028-São Francisco, submetida a 13 ciclos de seleção entre e dentro de progênies de meios-irmãos em diferentes municípios do estados de Sergipe e Bahia.

\section{Material e Métodos}

A população de milho CMS 28, proveniente do CIMMYT, foi introduzida no Brasil pela Embrapa-Centro Nacional de Pesquisa de Milho e Sorgo, tendo como principais características a cor branca dos grãos, reduzida altura de planta e de inserção da primeira espiga e grãos semidentados. Em 1978/1979 passou por um ciclo de seleção entre e dentro de progênies de meios-irmãos e, em 1980/1981, foi submetida a um ciclo com progênies de irmãos germanos. Na época da colheita do campo de recombinação, observou-se que dentro da população ocorria a segregação para grãos amarelos. Esses grãos foram selecionados para dar início à formação da variedade BR 5028-São Francisco, com coloração amarela. Após a recombinação, em lote isolado por despendoamento, uma amostra representativa dessas sementes amarelas foi enviada à Embrapa-Centro de Pesquisa Agropecuária dos Tabuleiros Costeiros, em Sergipe, para dar início a um programa de melhoramento.

Em 1984, foi semeada, em Gararu, SE, em uma área de $2.000 \mathrm{~m}^{2}$, efetuando-se no momento da colheita a seleção de 200 progênies competitivas, prolíficas, bem empalhadas, com baixa altura de planta e da inserção da espiga, e com grãos semidentados e amarelos. A seguir, foram realizados os ciclos de seleção: ciclo 0, em 1985, no Município de Gararu; ciclo I, em 1986, em Propriá e Gararu; ciclo II, em 1987, nos municípios de Propriá e Poço Verde.

Essas progênies foram avaliadas em dois látices simples $10 \times 10$, sendo as progênies de 1 a 100 colocadas no ensaio A, e de 101 a 200, no ensaio B. Entre os anos 1988 e 1990 essa população passou por três ciclos de seleção massal simples. No último ano de seleção massal, foram retiradas 196 progênies de meios-irmãos, obedecendo aos critérios já mencionados, para reiniciar o programa de melhoramento, utilizando-se o esquema de seleção entre e dentro de progênies de meios-irmãos. A seguir, foram realizados os ciclos VI: 1991 em Neópolis; VII: 1992 em Neópolis; VIII: 1994 em Neópolis e Umbaúba; IX: 1995 em Neópolis e Lagarto; X: 1996 em Nossa Senhora das Dores, Neópolis e Cruz das Almas; XI: 1997 em Nossa Senhora das Dores e Umbaúba; XII: 1998 em Nossa Senhora das Dores, Neópolis e Umbaúba; XIII: 1999 em Nossa Senhora das Dores e Neópolis; XIV: 2000 em Nos- 
sa Senhora das Dores e Neópolis; e XV: 2001 em Nossa Senhora das Dores e Neópolis. À exceção do Município de Cruz das Almas, localizado no Recôncavo Baiano, os demais estão localizados no Estado de Sergipe. Todos os municípios sergipanos estão localizados nos Tabuleiros Costeiros, em solos do tipo Latossolo Vermelho-Amarelo, o mesmo de Cruz das Almas. Nessa região, o período chuvoso ocorre de março/abril a setembro, com precipitação média entre $800 \mathrm{~mm}$ e $1.500 \mathrm{~mm}$ e temperatura média em torno de $26^{\circ} \mathrm{C}$. A implantação dos ensaios ocorreu na primeira quinzena de maio de cada ano agrícola.

Entre os ciclos VI e XV, as 196 progênies foram avaliadas em látices simples $14 \times 14$, com duas repetições. As parcelas nos ciclos original, I e II foram formadas por uma fileira de 5,0 $\mathrm{m}$ de comprimento, com 1,0 m entre fileiras e $0,5 \mathrm{~m}$ entre covas dentro das fileiras. Entre os ciclos VI e XV, cada parcela constou de uma fileira de 5,0 m de comprimento, com $0,9 \mathrm{~m}$ entre fileiras e $0,4 \mathrm{~m}$ entre covas, dentro das fileiras. Em todos os ciclos foram colocadas três sementes por cova, deixando-se duas plantas por cova, após o desbaste. A variedade testemunha, BR 106, foi colocada sistematicamente dentro de cada bloco, somando 14 parcelas em cada repetição. Nos anos em que os ensaios foram realizados em dois e três locais (ciclo XV), as progênies foram selecionadas na média dos locais. Após a realização dos ensaios, foi praticada intensidade de seleção de $10 \%$ entre progênies. As progênies selecionadas foram recombinadas em lotes isolados por despendoamento, e foram selecionadas 196 novas progênies, correspondendo a uma intensidade de seleção de $10 \%$ dentro das progênies, no mesmo ano agrícola. Todos os ensaios e campos de recombinação receberam adubação de acordo com os resultados das análises de solo de cada área experimental.

Nos ciclos original, I e II foram tomados os pesos de grãos em todos os ensaios. No ciclo original, quando as progênies foram avaliadas em um só local, as análises de variância foram feitas para cada látice em separado. A seguir, os quadrados médios dos tratamentos ajustados e do erro efetivo dos dois látices foram ponderados, originando a análise agrupada.

Nos ciclos I e II, com avaliações feitas em dois locais, além das análises individuais e agrupadas dentro de cada local, foi feita a análise de variância conjunta de locais, englobando os ensaios que possuíam as mesmas 100 progênies, utilizando-se as médias ajustadas das progênies e seguindo o modelo do delineamento em blocos ao acaso, conforme Vianna \& Silva (1978). Finalmente, foram calculados os quadrados médios de progênies, da interação progênies $\mathrm{x}$ locais e dos erros combinados das análises conjuntas, para reagrupar as 200 progênies numa só análise, denominada análise agrupada, conforme método utilizado por Pacheco (1987).

Os quadrados médios das análises agrupadas foram multiplicados pelo número de repetições, porque foram utilizadas as médias das progênies para efetuar as análises conjuntas que os geraram.

As estimativas dos parâmetros genéticos dentro de cada local e na média dos locais foram obtidas das análises combinadas e agrupadas, respectivamente, as quais tiveram os quadrados médios ajustados por indivíduo, obtendo-se, assim, todas as variâncias expressas em (g/planta) ${ }^{2}$, conforme as expressões apresentadas por Vencovsky (1978).

Após esses três ciclos iniciais de seleção entre e dentro de progênies de meios-irmãos, a variedade BR 5028-São Francisco passou por três ciclos de seleção massal, retomando-se a seguir a seleção com progênies de meios-irmãos, praticando-se dez novos ciclos de seleção, no período de 1991 a 2001.

Entre os ciclos VI e XV, foram considerados os pesos de espigas, os quais foram ajustados, em todos os ensaios, para $15 \%$ de umidade. Realizou-se inicialmente a análise por local, segundo o esquema em látice. Nos anos em que foram utilizados dois ou três locais, após a análise por local, procedeu-se a análise de variância conjunta, a partir das médias ajustadas dos tratamentos. Os quadrados médios das análises de variância por local e conjunta foram ajustados para indivíduos, obtendo-se todas as variâncias expressas em (g/planta) ${ }^{2}$, conforme Vencovsky (1978). Embora as análises tenham sido feitas em látice, as estimativas dos componentes da variância foram baseadas nas esperanças dos quadrados médios para blocos casualizados, fazendo-se uso efetivo do látice, usando os quadrados médios de tratamentos ajustados e o erro efetivo do látice, conforme método descrito por Vianna \& Silva (1978).

\section{Resultados e Discussão}

Na análise de variância combinada, com as progênies do ciclo original, observou-se significância nos tratamentos a $1 \%$ de probabilidade, evidenciando a presença de variabilidade genética entre as progênies avaliadas. $\mathrm{O}$ ciclo I, realizado em dois locais, mostrou diferenças significativas a $1 \%$ e a $5 \%$ de probabilidade, pelo teste $\mathrm{F}$, dos efeitos de ambientes e progênies e ausência de efeito significativo quanto à interação progênies x locais, o que revela que os 
ambientes e as progênies apresentaram comportamentos diferenciados, e as progênies, o mesmo comportamento em face das oscilações ambientais. No ciclo II, realizado também em dois locais, foram observadas diferenças em peso de grãos entre as progênies e os locais e comportamento diferenciado das progênies ante as oscilações ambientais.

Os resultados das análises de variância com progênies do ciclo VI ao ciclo XV apresentaram diferenças significativas a $1 \%$ de probabilidade, pelo teste $\mathrm{F}$, entre as progênies, em todos esses ciclos de seleção, o que evidencia a presença de variabilidade genética entre elas, em relação ao peso de espigas. A interação progênies x locais, significativa em ciclos realizados em dois e três locais, revela o comportamento diferenciado entre as progênies de cada ciclo, em face das variações ambientais. Os valores dos coeficientes de variação obtidos em todos esses ciclos de seleção conferiram boa precisão aos ensaios, conforme os critérios adotados por Scapim et al. (1995).

As produtividades médias obtidas nos ciclos de VI a XV de seleção com as 196 progênies avaliadas e com as 20 selecionadas foram de $6.003 \mathrm{~kg} / \mathrm{ha}$ e $7.387 \mathrm{~kg} / \mathrm{ha}$, respectivamente, o que atesta a alta capacidade produtiva dessa variedade (Tabela 1). As populações correspondentes aos ciclos VI, VII e VIII produziram menos que a variedade testemunha (BR 106).

A amplitude das produtividades médias encontradas entre as progênies de cada ciclo permite também visualizar o efeito da seleção nos níveis de produtividades das progênies (Tabela 1). Nos ciclos realizados, a seleção proporcionou o aparecimento de progênies mais produtivas com o desenvolvimento de novos ciclos de seleção. No ciclo VI, a progênie mais produtiva superou em $24 \%$ a média da variedade testemunha; no ciclo XV, essa superioridade foi de $58 \%$.

Obtiveram-se estimativas das variâncias entre progênies e aditiva mais altas no primeiro ciclo de seleção, mesmo considerando que no ciclo original essas estimativas foram obtidas em um só local (Tabela 2). Isto não era esperado, pois resultados relatados por Cunha (1968), Paterniani (1968) e Santos \& Naspolini Filho (1986) têm mostrado redução do ciclo original em relação ao ciclo I, com posterior estabilização nos demais ciclos.
As estimativas da variância genética entre progênies mostraram queda da variabilidade do ciclo VI ao ciclo XI, encontrando-se menores valores nos

Tabela 1. Comparação das produtividades médias de espigas das progênies avaliadas e selecionadas da variedade BR 5028-São Francisco entre os ciclos VI e XV, de seleção com a produtividade da testemunha BR 106, e médias ajustadas das progênies avaliadas em relação à variedade testemunha.

\begin{tabular}{|c|c|c|c|}
\hline Materiais & $\begin{array}{l}\text { Produtividade } \\
\text { média }\end{array}$ & Ciclos & $\begin{array}{l}\text { Porcentagem } \\
\text { em relação à } \\
\text { testemunha }\end{array}$ \\
\hline BR 106 & 5.673 & VI & 100 \\
\hline Progênies avaliadas & 4.788 & & 84 \\
\hline Progênies selecionadas & 6.128 & & 108 \\
\hline Amplitude de variação & 1.411 a 7.018 & & 25 a 124 \\
\hline Média ajustada ( $\mathrm{kg} / \mathrm{ha})$ & 5.013 & & \\
\hline BR 106 & 5.872 & VII & 100 \\
\hline Progênies avaliadas & 5.327 & & 91 \\
\hline Progênies selecionadas & 6.669 & & 114 \\
\hline Amplitude de variação & 3.345 a 7.456 & & 57 a 127 \\
\hline Média ajustada (kg/ha) & 5.353 & & \\
\hline BR 106 & 7.771 & VIII & 100 \\
\hline Progênies avaliadas & 6.659 & & 86 \\
\hline Progênies selecionadas & 8.605 & & 111 \\
\hline Amplitude de variação & 3.283 a 9.886 & & 43 a 128 \\
\hline Média ajustada (kg/ha) & 4.789 & & \\
\hline BR 106 & 5.790 & IX & 100 \\
\hline Progênies avaliadas & 6.463 & & 116 \\
\hline Progênies selecionadas & 7.801 & & 135 \\
\hline Amplitude de variação & 4.099 a 8.156 & & 71 a 141 \\
\hline Média ajustada $(\mathrm{kg} / \mathrm{ha})$ & 6.571 & & \\
\hline BR 106 & 6.739 & $\mathrm{X}$ & 100 \\
\hline Progênies avaliadas & 6.833 & & 101 \\
\hline Progênies selecionadas & 8.093 & & 120 \\
\hline Amplitude de variação & 5.223 a 8.412 & & 78 a 125 \\
\hline Média ajustada $(\mathrm{kg} / \mathrm{ha})$ & 5.898 & & \\
\hline BR 106 & 5.490 & XI & 100 \\
\hline Progênies avaliadas & 5.817 & & 106 \\
\hline Progênies selecionadas & 7.067 & & 129 \\
\hline Amplitude de variação & 4.019 a 7.652 & & 74 a 140 \\
\hline Média ajustada $(\mathrm{kg} / \mathrm{ha})$ & 6.225 & & \\
\hline BR 106 & 5.960 & XII & 100 \\
\hline Progênies avaliadas & 6.619 & & 111 \\
\hline Progênies selecionadas & 7.678 & & 129 \\
\hline Amplitude de variação & 5.111 a 8.067 & & 86 a 136 \\
\hline Média ajustada $(\mathrm{kg} / \mathrm{ha})$ & 6.557 & & \\
\hline BR 106 & 5.060 & XIII & 100 \\
\hline Progênies avaliadas & 5.288 & & 104 \\
\hline Progênies selecionadas & 6.812 & & 135 \\
\hline Amplitude de variação & 3.294 a 7.381 & & 65 a 146 \\
\hline Média ajustada (kg/ha) & 6.126 & & \\
\hline BR 106 & 5.023 & XIV & 100 \\
\hline Progênies avaliadas & 5.503 & & 110 \\
\hline Progênies selecionadas & 6.898 & & 137 \\
\hline Amplitude de variação & 3.283 a 7.843 & & 66 a 157 \\
\hline Média ajustada $(\mathrm{kg} / \mathrm{ha})$ & 6.378 & & \\
\hline BR 106 & 5.600 & $\mathrm{XV}$ & 100 \\
\hline Progênies avaliadas & 6.734 & & 120 \\
\hline Progênies selecionadas & 8.120 & & 145 \\
\hline Amplitude de variação & 4.637 a 8.848 & & 83 a 158 \\
\hline Média ajustada (kg/ha) & 7.032 & & \\
\hline
\end{tabular}


ciclos IX, X e XI, realizados em mais de um local, e portanto, menos influenciados pela interação progênies x locais. A partir do ciclo XII, detectouse acréscimo da variabilidade genética, permanecendo mais ou menos constante até o ciclo XV. Com quaisquer das estimativas, constata-se o mesmo comportamento da variabilidade genética. Segundo Webel \& Lonquist (1967), a queda inicial da variabilidade pode ser atribuída à redução das grandes diferenças entre as progênies de meios-irmãos na população original e na fixação de grande parte de genes maiores como resultado da seleção inicial. Moll \& Stuber (1974), citados por Bigoto (1988), verificaram que alguns trabalhos reportados não apresentam queda significativa na variabilidade genética. Concordando com essas afirmações, Hallauer (1981) relata resultados obtidos em seis programas de seleção nos Estados Unidos nos quais não ocorreu diminuição da variância genética aditiva com o avanço dos ciclos de seleção. Incrementos na variabilidade no decorrer dos ciclos de seleção podem ser causados pela liberação de variabilidade latente presente nos blocos poligênicos (Webel \& Lonquist, 1967). Os dados do presente trabalho corroboram a sugestão apresentada, pois, para que progressos contínuos tenham sido obtidos, nova variabilidade utilizável deve ter sido liberada.
Verificou-se que a variação detectada na variância genética aditiva acompanhou a variação da variância genética entre progênies, registrando-se os valores mais elevados nos ciclos VI e VII, quando a seleção foi efetuada em apenas um local, superando os valores relatados por Cunha (1968), Paterniani (1968), Ramalho (1977) e Aguiar (1986). As estimativas dessa variância nos ciclos original, I e II mostraram valores mais altos no ciclo original de seleção, mesmo considerando que nesse ciclo essas estimativas foram obtidas em um só local (Tabela 2). Isto não era esperado, pois resultados relatados por diversos autores têm mostrado redução do ciclo original em relação ao ciclo I, com posterior estabilização nos demais ciclos (Cunha, 1968; Silva, 1969; Carvalho et al., 2000a). As estimativas obtidas a partir das análises conjuntas dos ciclos VIII a XV estão compatíveis com as relatadas por Aguiar (1986), Pacheco (1987) e Carvalho et al. (2000a). Segundo Paterniani (1968), é do máximo interesse que a variância genética aditiva permaneça tão alta quanto possível, para permitir progressos substanciais por seleção. $\mathrm{O}$ autor comenta, ainda, que esse método de seleção reduz muito essa variância no primeiro ciclo de seleção, mas, apesar dessa redução, no decorrer dos ciclos de seleção, têm-se observado ganhos satisfatórios, a exemplo dos obtidos por Webel \& Lonnquist (1967).

Tabela 2. Estimativas obtidas em cada local e análises conjuntas, considerando os parâmetros peso de grãos nos ciclos original, I e II, e peso de espigas, nos demais ciclos de seleção, referentes à variância genética entre progênies $\left(\sigma_{\mathrm{p}}^{2}\right)$, variância genética aditiva $\left(\sigma_{\mathrm{A}}^{2}\right)$, variância da interação progênies x locais $\left(\sigma_{\mathrm{pxl}}^{2}\right)$, coeficiente de herdabilidade no sentido restrito de médias de progênies $\left(\mathrm{h}^{2} \mathrm{~m}\right)$, e quanto à seleção massal $\left(\mathrm{h}^{2}\right)$, coeficiente de variação genética $(\mathrm{CVg})$, índices de variação (b) e ganhos genéticos entre e dentro de progênies de meios-irmãos (Gs), com a variedade BR 5028-São Francisco. Região Nordeste, 1985 a 2001(1).

\begin{tabular}{|c|c|c|c|c|c|c|c|c|c|c|c|c|c|}
\hline \multirow[t]{2}{*}{ Ciclos } & \multirow[t]{2}{*}{ Locais } & $\sigma_{p}^{2}$ & $\sigma_{\mathrm{A}}^{2}$ & $\sigma_{\mathrm{pxl}}^{2}$ & $\mathrm{~h}_{\mathrm{m}}^{2}$ & $\mathrm{~h}^{2}$ & $\mathrm{CVg}$ & \multirow[t]{2}{*}{$\mathrm{b}$} & \multicolumn{2}{|c|}{$\begin{array}{l}\text { Gs entre } \\
\text { progênies }\end{array}$} & \multicolumn{2}{|c|}{$\begin{array}{l}\text { Gs dentro de } \\
\text { progênies }\end{array}$} & \multirow{2}{*}{$\begin{array}{c}\text { Gs total } \\
(\%) \\
\end{array}$} \\
\hline & & \multicolumn{3}{|c|}{-------- (g/planta $)^{2}$} & ------- & $(\%)-$ & -------- & & (g/planta) & $(\%)$ & (g/planta) & $(\%)$ & \\
\hline 0 & 1 & 101,3 & 405,0 & - & 56,5 & 22,4 & 7,9 & 0,7 & 13,3 & 10,5 & 6,3 & 4,9 & 15,4 \\
\hline I & 2 & 156,3 & 625,1 & 11,3 & 49,2 & 13,5 & 8,9 & 0,5 & 15,4 & 11,0 & 6,1 & 4,3 & 15,3 \\
\hline II & 2 & 2,4 & 9,6 & 38,8 & 4,2 & 1,0 & 2,1 & 0,1 & 0,6 & 0,8 & 0,2 & 0,3 & 1,1 \\
\hline VI & 1 & 456,8 & $1.827,1$ & - & 83,1 & 62,6 & 16,4 & 1,6 & 34,2 & 26,4 & 34,7 & 26,6 & 53,0 \\
\hline VII & 1 & 318,4 & $1.273,4$ & - & 67,4 & 50,2 & 12,7 & 1,0 & 25,7 & 18,3 & 18,7 & 13,3 & 31,6 \\
\hline VIII & 2 & 188,3 & 753,2 & 256,4 & 52,0 & 43,4 & 10,5 & 1,1 & 17,4 & 13,3 & 14,5 & 11,1 & 24,4 \\
\hline IX & 2 & 71,9 & 287,8 & 239,4 & 29,8 & 15,2 & 6,7 & 0,6 & 8,1 & 6,4 & 5,0 & 3,9 & 10,3 \\
\hline $\mathrm{X}$ & 3 & 80,4 & 321,7 & 135,7 & 80,8 & 21,5 & 7,2 & 0,7 & 14,1 & 11,2 & 6,2 & 4,9 & 16,1 \\
\hline XI & 2 & 25,7 & 102,6 & 76,9 & 28,5 & 11,4 & 4,7 & 0,5 & 4,8 & 4,4 & 2,5 & 2,3 & 6,7 \\
\hline XII & 3 & 78,3 & 313,2 & 204,2 & 45,6 & 22,0 & 6,7 & 0,7 & 1,0 & 7,8 & 5,1 & 3,8 & 11,6 \\
\hline XIII & 2 & 70,9 & 283,7 & 72,8 & 44,7 & 16,7 & 8,0 & 0,6 & 9,9 & 9,4 & 3,3 & 3,8 & 13,2 \\
\hline XIV & 2 & 91,2 & 364,7 & 189,6 & 40,4 & 24,3 & 9,2 & 0,7 & 10,6 & 10,3 & 7,2 & 6,9 & 17,2 \\
\hline $\mathrm{XV}$ & 2 & 113,4 & 453,8 & 211,3 & 47,9 & 16,3 & 8,4 & 0,6 & 12,9 & 10,2 & 6,3 & 5,0 & 15,2 \\
\hline
\end{tabular}

(1)Ciclo 0: 1985, Gararu; Ciclo I: 1986, Propriá e Gararu; Ciclo II: 1987, Propriá e Poço Verde; Ciclo VI: 1991, Neópolis; Ciclo VII: 1992, Neópolis; Ciclo VIII, 1994, Neópolis e Umbaúba; Ciclo IX: 1995, Neópolis e Lagarto; Ciclo X: 1996, Nossa Senhora das Dores, Neópolis e Cruz das Almas; Ciclo XI: 1997, Nossa Senhora das Dores e Umbaúba; Ciclo XII: 1998, Nossa Senhora das Dores, Neópolis e Umbaúba; Ciclo XIII: 1999, Nossa Senhora das Dores e Neópolis; Ciclo XIV: 2000, Nossa Senhora das Dores e Neópolis; Ciclo XV: 2001, Nossa Senhora das Dores e Neópolis. 
As estimativas da variância da interação progênies $x$ locais evidenciaram grandes divergências entre os locais e comportamento diferenciado das progênies nesses locais, principalmente nos ciclos VIII, IX, X, XII, XIV e XV de seleção (Tabela 2). Quando se pretende obter materiais genéticos para ambientes mais amplos, é necessário que a seleção seja baseada em avaliações realizadas em mais de um local, pois, selecionando-se em um só local, o ganho poderá estar superestimado. Hallauer \& Miranda Filho (1988) ressaltaram que esse componente da variância pode atingir mais de $50 \%$ da estimativa da variância genética entre progênies, e as estimativas dos parâmetros genéticos e fenotípicos obtidos em apenas um local são superestimados, pela existência do componente da variação resultante da interação progênies x local, que não pode ser isolado.

Os valores dos coeficientes de herdabilidade no sentido restrito com média de progênies de meios-irmãos $\left(\mathrm{h}_{\mathrm{m}}{ }_{\mathrm{m}}\right)$ superaram os obtidos nas próprias plantas $\left(\mathrm{h}^{2}\right)$, em todos os ciclos de seleção (Tabela 2). Isto indica que a variação genética existente entre indivíduos meios-irmãos é grande em relação à variância fenotípica, o que está de acordo com os relatos de Santos et al. (1998) e Carvalho et al. (2000a, 2000b, 2000c), sendo os valores mais altos obtidos em relação a local. As magnitudes dos coeficientes de variância genética mostraram que as populações dos ciclos VI, VII e VIII apresentaram variabilidade. Os coeficientes b retratam seleção mais favorável para a seleção no âmbito local. A finalidade principal do índice b, segundo Vencovsky (1987), é indicar se determinado material, numa dada fase de avaliação, se presta à seleção. De acordo com o autor, uma situação mais favorável para a seleção de progênies de milho é quando a estimativa de b apresenta valor próximo ou superior à unidade.

Não houve redução na estimativa do ganho esperado com a seleção entre e dentro de progênies de meios-irmãos do ciclo original para o ciclo I de seleção, mesmo considerando que no ciclo original essas estimativas foram obtidas em um só local, capitalizando a interação progênies x locais (Tabela 2).

As estimativas do progresso genético esperado entre e dentro de progênies de meios-irmãos, no decorrer dos ciclos VI ao XV foram, em média, 11,8\% e $8,25 \%$, respectivamente, sendo $20,0 \%$ o ganho médio ciclo/ano. Desconsiderando os valores encontrados nos ciclos VI e VII, realizados em um só local, por isso influenciados pela interação progênies x locais, as estimativas dos ganhos genéticos esperados entre e dentro de progênies de meios-irmãos foram de $9,1 \%$ e $5,2 \%$, respectivamente, totalizando $14,3 \%$ o ganho esperado ciclo/ano, o que confirma o potencial genético da variedade BR 5028-São Francisco em responder à seleção para aumento da produtividade de espigas.

Após ajustar as médias dos ciclos de progênies avaliadas para torná-las comparáveis, o ganho acumulado entre os ciclos VI e XV foi de $2.019 \mathrm{~kg} / \mathrm{ha}$, equivalente a $40,27 \%$, o que fornece um ganho/ciclo/ano de $201,9 \mathrm{~kg} / \mathrm{ha}$, correspondendo a 4,03\% (Tabela 2).

\section{Conclusão}

As médias de produtividades e as magnitudes das estimativas dos parâmetros genéticos das progênies evidenciam que a variedade BR 5028-São Francisco possui alta variabilidade genética.

\section{Referências}

AGUIAR, P. A. Avaliação de progênies de meios-irmãos de milho CMS-39 em diferentes condições de ambientes. 1986. 68 f. Dissertação (Mestrado em Genética e Melhoramento de Plantas) - Escola Superior de Agricultura de Lavras, Lavras, 1986.

BIGOTO, C. A. Estudo da população ESALQ-PB I de milho (Zea mays L.) em cinco ciclos de seleção recorrente. 1988. 122 f. Dissertação (Mestrado em Genética e Melhoramento de Plantas) - Escola Superior de Agricultura Luiz de Queiroz, Piracicaba, 1988.

CARVALHO, H. W. L. de; GUIMARÃES, P. E. de O.; LEAL, M. de L. da S.; CARVALHO, P. C. L. de; SANTOS, M. X. dos. Avaliação de progênies de meios-irmãos da população de milho CMS-453 no Nordeste brasileiro. Pesquisa Agropecuária Brasileira, Brasília, v. 35, n. 8, p. 1577-1584, ago. 2000a.

CARVALHO, H. W. L. de; LEAL, M. de L. da S.; GUIMARÃES, P. E. de O.; SANTOS, M. X. dos; CARVALHO, P. C. L. de. Três ciclos de seleção entre e dentro de progênies de meios-irmãos na população de milho CMS-52. Pesquisa Agropecuária Brasileira, Brasília, v. 35, n. 8, p. 1621-1628, ago. 2000b.

CARVAlHO, H. W. L. de; LEAL, M. de L. da S.; PACHECO, C. A. P.; SANTOS, M. X. dos. Estimativas de parâmetros genéticos em dois ciclos de seleção entre e 
dentro de progênies e meios-irmãos na população de milho CMS 453, de alta qualidade protéica. Revista Científica Rural, Bagé, v. 6, n. 1, p. 77-84, 2001.

CARVALHO, H. W. L. de; LEAL, M. de L. da S.; SANTOS, M. X. dos; PACHECO, C. A. P. Potencial genético da cultivar de milho BR 5011-Sertanejo no Nordeste brasileiro. Pesquisa Agropecuária Brasileira, Brasília, v. 35, n. 6, p. 1169-1176, jun. 2000c.

CARVALHO, H. W. L. de; SANTOS, M. X. dos; LEAL, M. de L. da S.; CARVALHO, P. C. L. de. Melhoramento genético da cultivar de milho BR 5033-Asa Branca no Nordeste brasileiro. Pesquisa Agropecuária Brasileira, Brasília, v. 35, n. 7, p. 1417-1425, jul. 2000d.

CUNHA, M. A. P. da. Seleção entre e dentro de progênies de meios-irmãos de milho (Zea mays L.) ESALQ HV-1. 1968. 84 f. Dissertação (Mestrado em Genética e Melhoramento de Plantas) - Escola Superior de Agricultura Luiz de Queiroz, Piracicaba, 1968.

HALLAUER, A. R. Selection and breeding methods. In: FREY, K. S. (Ed.). Plant breeding II. Ames: Iowa State University Press, 1981. p. 3-55.

HALLAUER, A. R.; MIRANDA FILHO, J. B Quantitative genetics in maize breeding. $2^{\text {nd }}$ ed. Ames: Iowa State University Press, 1988. 468 p.

PACHECO, C. A. P. Avaliação de progênies de meiosirmãos na população de milho CMS 39 em diferentes condições de ambiente: $2^{\circ}$ ciclo de seleção. 1987. 109 f. Dissertação (Mestrado em Genética e Melhoramento de Plantas) - Escola Superior de Agricultura de Lavras, Lavras, 1987.

PATERNIANI, E. Avaliação de métodos de seleção entre e dentro de famílias de meios-irmãos no melhoramento de milho (Zea mays L.). 1968. 92 f. Dissertação (Mestrado em Genética e Melhoramento de Plantas) - Escola Superior de Agricultura Luiz de Queiroz, Piracicaba, 1968.

RAMALHO, M. A. P. Eficiência relativa de alguns processos de seleção intrapopulacional no milho baseados em famílias não endógamas. 1977. 122 f. Dissertação (Mestrado em Genética e Melhoramento de Plantas) - Escola Superior de Agricultura Luiz de Queiroz, Piracicaba, 1977.
SANTOS, M. X. dos; GUIMARÃES, P. E.; PACHECO, C. A. P.; FRANÇA, G. E.; PARENTONI, S. N.; GAMA, E. E. G.; LOPES, M. A. Melhoramento intrapopulacional no sintético elite NT para solo pobre em nitrogênio. Pesquisa Agropecuária Brasileira, Brasília, v. 33, n. 1, p. 5561, jan. 1998.

SANTOS, M. X. dos; NASPOLINI FILHO, W. Estimativas de parâmetros genéticos em três ciclos de seleção entre e dentro de progênies de meios-irmãos no milho (Zea mays L.) dentado composto nordeste. Revista Brasileira de Genética, Ribeirão Preto, v. 9, n. 2, p. 307-319, 1986.

SAWAZAKI, E. Treze ciclos de seleção entre e dentro de famílias de meios-irmãos para a produção de grãos no milho IAC Maia. 1979. 99 f. Dissertação (Mestrado em Genética e Melhoramento de Plantas) - Escola Superior de Agricultura Luiz de Queiroz, Piracicaba, 1979.

SCAPIM, C. A.; CARVALHO, C. G. P.; CRUZ, C. D. Uma proposta de classificação dos coeficientes de variação para a cultura do milho. Pesquisa Agropecuária Brasileira, Brasília, v. 30, n. 5, p. 683-686, maio 1995.

SILVA, S. Seleção entre e dentro de famílias de meiosirmãos no milho cateto colômbia composto. 1969. 74 f. Dissertação (Mestrado em Genética e Melhoramento de Plantas) - Escola Superior de Agricultura Luiz de Queiroz, Piracicaba, 1969.

VENCOVSKY, R. Herança quantitativa. In: PATERNIANI, E. (Ed.). Melhoramento e produção do milho no Brasil. Piracicaba: Escola Superior de Agricultura Luiz de Queiroz, 1978. p. 122-201.

VENCOVSKY, R. Herança quantitativa. In: PATERNIANI, E.; VIEGAS, G. P. Melhoramento e produção do milho. 2. ed. Campinas: Fundação Cargill, 1987. p. 137-214.

VIANNA, R. T.; SILVA, J. C. Comparação de três métodos estatísticos de análise de variância em experimentos em látice em milho (Zea mays L.). Experientiae, Viçosa, MG, v. 24, p. 21-41, 1978.

WEBEL, O. D.; LONQUIST, J. H. An evaluation of modified ear-to-row selection in a population of corn (Zea mays L.). Crop Science, Madison, v. 7, p. 651-655, 1967. 